\title{
PENGARUH VARIASI PENGGUNAAN ABU AMPAS TEBU (AAT) DAN ABU BATU (AB) SEBAGAI BAHAN PENGGANTI SEBAGIAN SEMEN TERHADAP KUAT TEKAN MORTAR
}

(Kajian terhadap Adukan Mortar 1Pc : 3Ps)

\author{
Rara Ayu Sati ${ }^{1)}$, Fepy Supriani ${ }^{2)}$, Yuzuar Afrizal $^{3)}$ \\ ${ }^{1), 2), 3)}$ Program Studi Teknik Sipil, Fakultas Teknik, Universitas Bengkulu \\ Corresponding Author: raraayusati@gmail.com
}

\begin{abstract}
Abstrak
Abu ampas tebu dan abu batu merupakan bahan yang sebagian unsurnya memiliki kesamaan dengan semen yaitu silika $\left(\mathrm{SiO}_{2}\right)$. Ampas tebu merupakan limbah yang belum dimanfaatkan oleh masyarakat. Abu batu merupakan limbah pabrik batu pecah yang penggunaannya dalam struktur bangunan gedung masih kurang. Penelitian ini bertujuan untuk mengetahui kuat tekan mortar yang menggunakan abu ampas tebu dan abu batu sebagai bahan pengganti sebagian semen. Metode pembuatan dan pengujian kuat tekan mortar mengacu pada SNI 03-6825-2002. Jumlah keseluruhan benda uji 128 sampel dengan dimensi yang digunakan $50 \mathrm{~mm}$ x $50 \mathrm{~mm}$ x $50 \mathrm{~mm}$. Variasi abu ampas tebu dan abu batu yang digunakan adalah 5\%,10\%, 15\%, 20\% dan 25\% dari berat semen yang digunakan. Rentang nilai initial flow yang digunakan yaitu 105\%-115\% (SNI 03-6882-2002). Kubus mortar direndam selama 27 hari dan pengujian mortar dilakukan pada umur 28 hari. Nilai kuat tekan mortar variasi AAT mengalami penurunan dari kuat tekan mortar normal dengan persentase penurunan berturut-turut sebesar $0,62 \%, 2,14 \%, 7,33 \%, 7,50 \%$ dan 9,53\%. Nilai kuat tekan mortar variasi $\mathrm{AB}$ mengalami kenaikan dari mortar normal pada variasi 5\%, $10 \%$ dan $15 \%$ dengan persentase kenaikan berturut-turut sebesar 4,66\%, 3,41\% dan 2,38\%, sedangkan pada variasi $20 \%$ dan $25 \%$ mengalami penurunan. Nilai kuat tekan mortar variasi campuran AAT dan AB mengalami penurunan dari mortar normal dengan persentase penurunan berturut-turut sebesar 0,08\%, 1,04\%, $5,67 \%, 8,06 \%$ dan $15,12 \%$.
\end{abstract}

Kata kunci: mortar, abu ampas tebu, abu batu, kuat tekan

\begin{abstract}
Bagasse ash and stone ash are materials that have some elements that fimilar to cement elements. Bagasse ash is a waste that has not been utilized by community. Stone ash is a waste of stone crusher whose utilization in building structures is still lacking. This research was aimed to know compressive strength of the mortar which use bagasse ash and stone ash as a partial substitute of cement. The method of casting and compressive strength test of the mortar referred to SNI 03-68252002. The total of mortar cubes was 128 specimens with dimensions of $50 \mathrm{~mm} \times 50 \mathrm{~mm} \times 50 \mathrm{~mm}$. Variations of bagasse ash and stone ash used were 5\%, 10\%, 15\%, 20\% and 25\% of the weight of cement.The range of initial flow values used are 105\%-115\% (SNI 03-6882-2002). Mortar cubes cured for 27 days and test of mortar was conducted at $28^{\text {th }}$ days. The value of mortar compressive strength variation of bagasse ash decrease from normal mortar compressive strength with a decrease respectively of $0.62 \%, 2.14 \%, 7.33 \%, 7.50 \%$ dan 9.53\%. Compressive strengths of mortar with stone ash is increases from normal mortar in variations 5\%, $10 \%$ and $15 \%$ with the percentages of $4.66 \%, 3.41 \%$ and $2.38 \%$ respectively, while in the variation of $20 \%$ and $25 \%$ is decreases. Compressive strength of mortar with mixture bagasse ash and stone ash reduce from normal mortar with a decrease of 0.08\%, 1.04\%, 5.67\%, 8.06\% dan $15.12 \%$ respectively.
\end{abstract}

Keywords: mortar, bagasse ash, stone ash, compressive strength 


\section{PENDAHULUAN}

Mortar adalah campuran antara agregat halus (pasir), air dan bahan perekat (semen portland) dengan komposisi tertentu. Mortar sebagai perekat untuk konstruksi struktural digunakan untuk pasangan batu pecah pada pondasi. Mortar untuk konstruksi nonstruktural digunakan pada pasangan bata untuk pengisi dinding. Kuat tekan mortar dipengaruhi oleh beberapa faktor yaitu kepadatan, umur mortar, jenis semen, dan sifat agregat (SNI 03-6825-2002).

Semen adalah bahan perekat yang berbentuk halus jika ditambahkan air akan terjadi reaksi hidrasi dan dapat mengikat bahanbahan padat menjadi satu kesatuan massa yang kokoh. Persentase terbesar dalam kandungan semen adalah $\mathrm{CaO}$ (kalsium oksida) kisaran 60\%-65\%, $\mathrm{SiO}_{2}$ (silika) kisaran 20\%-24\% dan $\mathrm{Al}_{2} \mathrm{O}_{3}$ (aluminium oksida) kisaran 4\%-8\% (Marzuki, 2009).

Tebu di Bengkulu oleh masyarakat dimanfaatkan sebagai bahan dasar minuman es tebu. Batang tebu diperas hingga menghasilkan air (nira) dan ampas tebu, nira dimanfaatkan sebagai pemanis dan bahan utama es tebu sedangkan ampasnya hanya dibuang atau dijadikan pupuk. Pembakaran ampas tebu akan menghasilkan abu ampas tebu yang memiliki kandungan senyawa silika ( $\mathrm{SiO} 2)$ yang juga merupakan bahan baku utama dari semen biasa (portland) (Mulyati dkk., 2012). Abu ampas tebu memiliki kandungan silika yang sangat tinggi mencapai 72,33\% (Pandaleke, 2014).

Abu batu $(\mathrm{AB})$ merupakan hasil sampingan dari produksi batu pecah. Abu batu merupakan abu yang mengandung banyak silika, alumina dan mengandung senyawa alkali, besi dan kapur walaupun dalam kadar yang rendah. Penggunaan abu batu sebagai semen dalam campuran adukan beton juga dapat meningkatkan kuat tekan beton (Wikana dan Wantutrianus, 2014).

Penelitian ini membahas pengaruh variasi penggunaan $100 \%$ AAT, $100 \%$ AB dan pecampuran 50\% AAT dan 50\% AB sebagai pengganti sebagian semen.Variasi campuran yang digunakan sebesar 5\%, 10\%, 15\%, $20 \%$ dan $25 \%$ dari berat semen yang digunakan. Perbandingan semen dan pasir yang digunakan pada penelitian ini yaitu $1 \mathrm{Pc}$ : 3Ps. Jumlah sampel benda uji per variasi adalah sebanyak 8 sampel.

\section{METODE PENELITIAN}

Tahapan pelaksanaan penelitian meliputi pemeriksaan bahan campuran mortar dengan melakukan uji fisis, perhitungan kebutuhan bahan untuk adukan mortar, pembuatan benda uji, perawatan, dan pengujian kuat tekan.

\section{Pemeriksaan abu ampas tebu}

Abu ampas tebu didapatkan dari proses pembakaran ampas tebu yang sebelumnya dikumpulkan dari para penjual es tebu di sekitar Kota Bengkulu. Abu ampas tebu dibakar secara langsung di atas api, dengan sebelumnya dijemur di bawah sinar matahari sampai memiliki berat yang tetap. Abu ampas tebu yang telah dibakar selanjutnya dilakukan pemeriksan analisa saringan lolos saringan No.200. Abu ampas tebu dicampurkan pada adukan mortar bersamaan dengan pencampuran semen. Abu ampas tebu dapat dilihat pada Gambar 1.

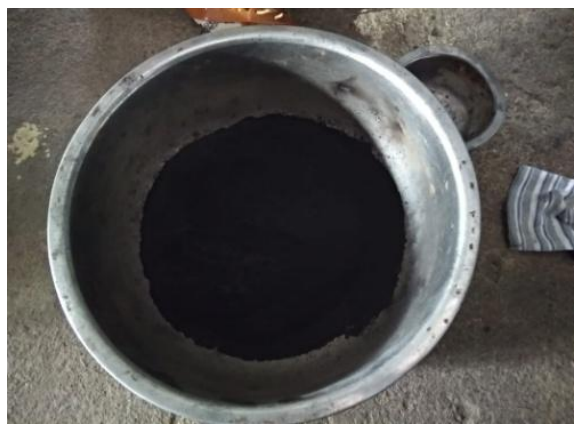

Gambar 1. Abu Ampas Tebu 


\section{Pemeriksaan Abu Batu}

Abu batu (Gambar 2) diambil dari stone crusher yang kemudian dioven untuk menghilangkan kadar air dan memudahkan saat penyaringan. Abu batu dilakukan pemeriksaan analisa saringan lolos saringan No.200.

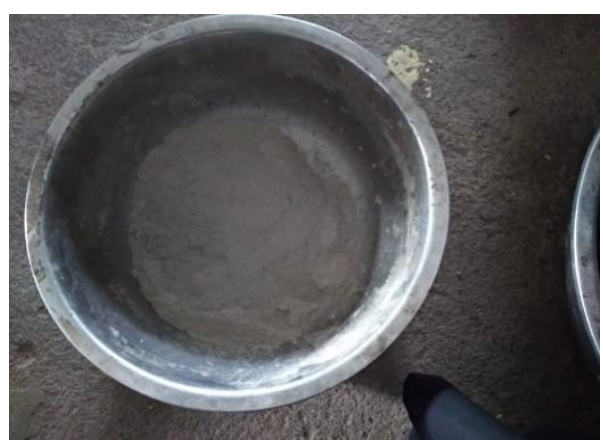

Gambar 2. Abu Batu

\section{Pemeriksaan agregat halus dan semen}

Agregat halus yang digunakan adalah pasir gunung yang diambil dari daerah Curup. Pemeriksaan material yang dilakukan untuk agregat halus:

a. Pemeriksaan gradasi (analisa saringan) mengacu pada SNI 03-1968-1990.

b. Pemeriksaan kadar air mengacu pada SNI 03-1971-1990.

c. Pemeriksaan kadar lumpur mengacu pada SNI 03-4142-1996.

d. Pemeriksaan berat jenis mengacu pada SNI 03-1970-1990.

e. Pemeriksaan berat isi mengacu pada SNI 03-4804-1998.

f. Pemeriksaan kadar organik mengacu pada SNI 03-2816-1992.

Rangkuman hasil pemeriksaan agregat halus dapat dilihat pada Tabel 1.

Tabel 1. Pemeriksaan Agregat Halus

\begin{tabular}{|c|c|}
\hline Nama Pengujian & Hasil Pengujian \\
\hline MHB (\%) & 1,68 \\
\hline Kadar Air (\%) & 1,63 \\
\hline KadarLumpur(\%) & 3,78 \\
\hline Berat Jenis (SSD) & 2,51 \\
\hline Berat Isi (gr/cm $\left.{ }^{3}\right)$ & 1,65 \\
\hline Apsorpsi (\%) & 2,62 \\
\hline
\end{tabular}

Semen yang digunakan adalah PCC yang sesuai dengan standar SNI 15-7064-2004.

\section{Pembuatan benda uji}

Semua bahan untuk adukan campuran mortar seperti agregat halus (pasir), semen PCC, abu ampas tebu, abu batu dan air diletakkan dalam tempat yang terpisah. Jumlah sampel benda uji setiap variasi dari abu ampas tebu dan abu batu dapat dilihat pada Tabel 2.

Tabel 2. Jumlah Benda Uji Mortar

\begin{tabular}{|l|c|c|c|c|}
\hline \multirow{2}{*}{ No } & \multirow{2}{*}{$\begin{array}{c}\text { Variasi } \\
\text { Campuran }\end{array}$} & \multicolumn{3}{|c|}{ Jumlah Benda Uji } \\
\cline { 3 - 5 } & AAT & AB & $\begin{array}{c}50 \% \\
\text { (AAT + AB) }\end{array}$ \\
\hline 1. & $5 \%$ & 8 & 8 & 8 \\
\hline 2. & $10 \%$ & 8 & 8 & 8 \\
\hline 3. & $15 \%$ & 8 & 8 & 8 \\
\hline 4. & $20 \%$ & 8 & 8 & 8 \\
\hline 5. & $25 \%$ & 8 & 8 & 8 \\
\hline Jumlah & 40 & 40 & 40 \\
\hline Jumlah Total & \multicolumn{4}{|c|}{120} \\
\hline Mortar Normal & \multicolumn{4}{|c|}{8} \\
\hline $\begin{array}{l}\text { Jumlah Total + } \\
\text { Normal }\end{array}$ \\
\hline
\end{tabular}

\section{Pengadukan mortar dan uji initial flow}

Pengadukan semen, abu ampas tebu, abu batu dan pasir dilakukan menggunakan mixer mortar. Air dimasukkan secara bertahap setelah campuran tersebut homogen. Pengecekan initial flow hingga mencapai rentang 105\% - 115\%, apabila campuran tidak mencapai rentang maka akan dilakukan penambahan air dan apabila melewati rentang yang ditentukan maka campuran tidak bisa dipakai. Pengecekan initial flow dihitung dengan rumus (SNI 036882-2002):

$$
\frac{d_{1}-d_{0}}{d_{0}} \times 100=105 \%-115 \%
$$

Keterangan:

$\mathrm{d} 1$ = diameter rata-rata setelah 25 ketukan.

$\mathrm{d} 0=$ diamater awal

\section{Pencetakan benda uji}

Adukan mortar dimasukkan kedalam cetakan menggunakan sendok semen. Pengisian dilakukan dalam 2 lapis, setiap 
lapis dipadatkan sebanyak 32 kali dengan alat pemadat. Adukan yang telah dituang ke dalam cetakan diratakan agar bagian atas menjadi rata. Cetakan mortar dibuka setelah 24 jam. Kubus mortar diberi tanda untuk membedakan kubus mortar yang telah dicetak sehingga tidak akan keliru.

\section{Perawatan benda uji}

Perawatan benda uji sesuai dengan SNI 03-6825-2002 dilakukan dengan perendaman dalam bak yang berisi air setelah mortar dikeluarkan 24 jam dari cetakan. Benda uji direndam selama 27 hari. Umur 28 hari benda uji dikeluarkan dari dalam air kemudian permukaannya dikeringkan dengan cara di lap dan dibiarkan selama \pm 15 menit, selanjutnya dilakukan pengujian kuat tekan mortar.

\section{Pelaksanaan pengujian}

Pengujian kuat tekan mortar sesuai dengan SNI 03-6825-2002 dilakukan saat berumur 28 hari. Pengukuran dimensi dan penimbangan berat benda uji dilakukan terlebih dahulu. Semua data yang bersangkutan dengan benda uji dicatat pada lembar yang telah disediakan. Alat yang digunakan pada pengujian mortar adalah Cement Compression Machine dengan kapasitas kuat tekan $250 \mathrm{kN}$ dan ketelitian $0,5 \mathrm{kN}$.

\section{HASIL DAN PEMBAHASAN}

\section{Hasil pengujian initial flow}

Tujuan pengujian initial flow adalah untuk mengetahui tingkat kelecakan adukan mortar yang dapat mempengaruhi workability. Pengujian intial flow dilakukan sesuai SNI 03-6882-2002, dengan nilai yang disyaratkan sebesar 105\% - 115\%. Nilai initial flow ditetapkan pada penelitian ini yaitu sebesar $105 \%$ - 110\%. Hasil pengujian initial flow dapat dilihat pada Tabel 3.
Tabel 2. Hasil Uji Initial Flow

\begin{tabular}{|c|c|c|c|}
\hline No & \multicolumn{2}{|c|}{ Variasi } & $\begin{array}{c}\text { Nilai Initial Flow } \\
(\%)\end{array}$ \\
\hline 1. & \multicolumn{2}{|c|}{ Normal } & 110,00 \\
\hline \multirow{5}{*}{2.} & \multirow{5}{*}{$\begin{array}{l}100 \% \\
\text { AAT }\end{array}$} & $5 \%$ & 112,50 \\
\hline & & $10 \%$ & 105,00 \\
\hline & & $15 \%$ & 105,00 \\
\hline & & $20 \%$ & 111,25 \\
\hline & & $25 \%$ & 115,00 \\
\hline \multirow{5}{*}{3.} & \multirow{5}{*}{$\begin{array}{c}100 \% \\
\mathrm{AB}\end{array}$} & $5 \%$ & 107,50 \\
\hline & & $10 \%$ & 110,00 \\
\hline & & $15 \%$ & 110,00 \\
\hline & & $20 \%$ & 107,50 \\
\hline & & $25 \%$ & 108,75 \\
\hline \multirow{5}{*}{4.} & \multirow{5}{*}{$\begin{array}{c}50 \% \\
\text { (AAT } \\
\text { dan } \\
\text { AB) }\end{array}$} & $5 \%$ & 106,25 \\
\hline & & $10 \%$ & 111,25 \\
\hline & & $15 \%$ & 108,75 \\
\hline & & $20 \%$ & 108,75 \\
\hline & & $25 \%$ & 106,25 \\
\hline
\end{tabular}

\section{Hasil pengujian kuat tekan mortar}

Hasil yang diperoleh pada penelitian ini yaitu nilai kuat tekan mortar bervariasi untuk berbagai variasi campuran. Pengaruh penggunaan abu ampas tebu dan abu batu sebagai bahan pengganti sebagian semen pada mortar adukan 1Pc : 3Ps dengan berbagai variabel mengalami peningkatan dan penurunan. Persentase peningkatan dan penurunan kuat tekan mortar variasi terhadap mortar normal dapat dilihat pada Gambar 3. Hasil uji kuat tekan mortar dapat dilihat pada Tabel 3 .

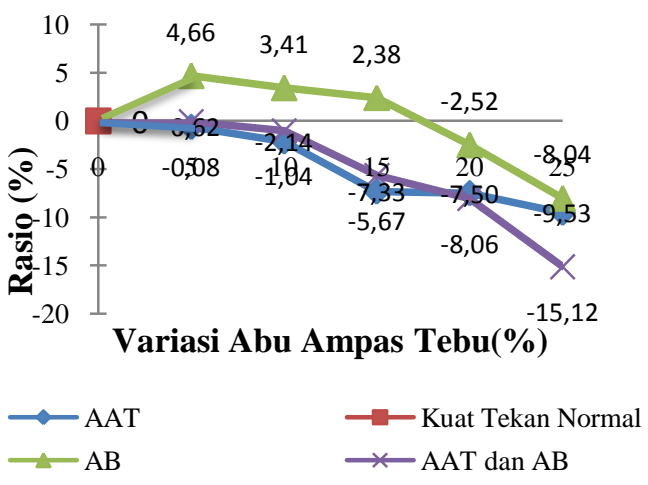

Gambar 3. Persentase Peningkatan dan Penurunan Kuat Tekan Mortar Variasi terhadap Mortar Normal 
Tabel 3. Hasil Uji Kuat Tekan Mortar

\begin{tabular}{|c|c|c|c|}
\hline No & \multicolumn{2}{|c|}{ Variasi } & $\begin{array}{c}\text { Kuat Tekan } \\
\quad(\mathrm{MPa})\end{array}$ \\
\hline 1. & \multicolumn{2}{|c|}{ Normal } & 18,17 \\
\hline \multirow{5}{*}{2.} & \multirow{5}{*}{$\begin{array}{l}100 \% \\
\text { AAT }\end{array}$} & $5 \%$ & 18,05 \\
\hline & & $10 \%$ & 17,78 \\
\hline & & $15 \%$ & 16,84 \\
\hline & & $20 \%$ & 16,80 \\
\hline & & $25 \%$ & 16,44 \\
\hline \multirow{5}{*}{3.} & \multirow{5}{*}{$\begin{array}{c}100 \% \\
\mathrm{AB}\end{array}$} & $5 \%$ & 19,01 \\
\hline & & $10 \%$ & 18,79 \\
\hline & & $15 \%$ & 18,60 \\
\hline & & $20 \%$ & 17,71 \\
\hline & & $25 \%$ & 16,71 \\
\hline \multirow{5}{*}{4.} & \multirow{5}{*}{$\begin{array}{c}50 \% \text { AAT } \\
\text { dan } \\
50 \% \text { AB }\end{array}$} & $5 \%$ & 18,15 \\
\hline & & $10 \%$ & 17,98 \\
\hline & & $15 \%$ & 17,14 \\
\hline & & $20 \%$ & 16,70 \\
\hline & & $25 \%$ & 15,42 \\
\hline
\end{tabular}

Nilai kuat tekan mortar variasi masinmasing variabel berbeda-beda. Kuat tekan mortar variasi tertinggi terjadi pada penggunaan abu batu sebagai bahan pengganti sebagian semen. Nilai kuat tekan mortar penggunaaan $\mathrm{AB} 5 \%, 10 \%, 15 \%$, $20 \%$ dan $25 \%$ adalah berturut-turut sebesar 19,01 MPa, 18,79 MPa, 18,60 MPa, 17,71 MPa dan 16,71 MPa. Penggunaan AB juga mengalami kenaikan kuat tekan dari kuat tekan mortar normal $(18,17 \mathrm{MPa})$ pada variasi $5 \%, 10 \%$ dan $15 \%$ dengan persentase kenaikan sebesar 4,66\%, 3,41\% dan 2,38\%, sedangkan turun $2,52 \%$ dan $8,04 \%$ pada variasi $20 \%$ dan $25 \%$.

Penggunaan abu ampas tebu mengakibatkan turunnya kuat tekan mortar di setiap variasi yan digunakan, baik dalam penggunaan $100 \%$ AAT maupun campuran 50\% AAT dan AB. Penggunaan $100 \%$ AAT pada variasi $5 \%, 10 \%$ dan $15 \%$ nilai kuat tekan yang dihasilkan lebih kecil dibandingkan dengan campuran 50\% AAT dan AB pada variasi yang sama. Variasi $20 \%$ dan $25 \%$ kuat tekan mortar variasi AAT lebih tinggi dibandingkan variasi mortar campuran 50\% AAT dan 50\% AB.

Nilai kuat tekan tertinggi terjadi pada penggunaan $100 \%$ AB sebagai bahan pengganti sebagian semen dengan nilai kuat tekan sebesar 19,01 $\mathrm{MPa}$ dan persentase kenaikan adalah sebesar $4,66 \%$. Nilai kuat tekan terendah terjadi pada penggunaan campuran 50\% AAT dan AB variasi $25 \%$ dengan nilai sebesar $15,42 \mathrm{MPa}$ persentasi penurunan sebesar $15,12 \%$.

Penurunan nilai kuat tekan mortar terjadi pada setiap penggunaan abu ampas tebu, sehingga dapat dikatakan bahwa penggunaan abu ampas tebu tidak memberikan dampak yang positif terhadap kuat tekan mortar. Penggunaan abu ampas tebu yang semakin tinggi maka akan menyebabkan semakin rendah kuat tekan mortar. Perlakuan terhadap abu ampas tebu saat proses pembakarannya kemungkinan besar memicu terjadinya penurunan kuat tekan mortar. Penggunaan silika yang berlebihan juga akan membawa dampak negatif pada mortar (Herlina dalam Mulyati dkk., 2012).

Penggunaan abu batu sebagai bahan pengganti sebagian semen dapat memberikan dampak yang positif terhadap kuat tekan mortar, namun penggunaan yang berlebihan juga tidak berdampak positif. Abu batu yang memiliki unsur yang hampir mirip dengan semen mampu meningkatkan kekuatan mortar. Umumnya komposisi abu batu tidak jauh berbeda dari semen yang bersifat mengikat (Bell dalam Rachman, 2015).

\section{KESIMPULAN}

1. Nilai kuat tekan mortar variasi AAT $(5 \%, 10 \%, 15 \%, 20 \%$ dan 25\%) mengalami penurunan dari kuat tekan 
mortar normal dengan persentase penurunan berturut-turut sebesar $0,62 \%$, $2,14 \%, 7,33 \%, 7,50 \%$ dan $9,53 \%$.

2. Nilai kuat tekan mortar variasi AB mengalami kenaikan dari mortar normal pada variasi $5 \%, 10 \%$ dan $15 \%$ dengan persentase kenaikan berturut-turut sebesar 4,66\%, 3,41\% dan 2,38\%, sedangkan pada variasi $20 \%$ dan $25 \%$ mengalami penurunan.

3. Nilai kuat tekan mortar variasi campuran $50 \%$ AAT dan 50\% AB (5\%, 10\%, 15\%, $20 \%$ dan 25\%) mengalami penurunan dari mortar normal dengan persentase penurunan berturut-turut sebesar $0,08 \%$, $1,04 \%, 5,67 \%, 8,06 \%$ dan $15,12 \%$.

4. Kuat tekan mortar terbesar terjadi pada penggunaan $\mathrm{AB} 5 \%$ dengan besar kuat tekan adalah 19,01 MPa naik 4,66\% dari kuat tekan mortar normal sebesar 18,17 $\mathrm{MPa}$.

\section{DAFTAR PUSTAKA}

Marzuki, I., 2009. Analisis Penambahan Additive Batu Gamping terhadap Kualitas Komposisi Kimia Semen Portland. Chemica, 10(1), pp.64-70.

Mulyadi, S. and Dahlan, D., 2012. Pengaruh Persen Massa Hasil Pembakaran Serbuk Kayu dan Ampas Tebu pada Mortar terhadap Sifat Mekanik dan Sifat Fisisnya. Jurnal Ilmu Fisika, Universitas Andalas, 4(1), pp.31-39.

Pandeleke, R.E., 2014. Kajian Experimental Sifat Karekteristik Mortar yang Menggunakan Abu Ampas Tebu sebagai Substitusi Parsial Semen. Tekno, 12(60).

Rachman, F., 2015, Penggunaan Abu Sekam Padi dan Abu Batu pada Pembuatan
Genteng Beton, Digital Repository Universitas Jember, pp. 15-16.

SNI 03-1968-1990. Metode Pengujian Analisis Saringan Agregat Halus dan Kasar. Departemen Pekerjaan Umum Yayasan Badan Penerbit PU.

SNI 03-1970-1990. Metode Pengujian Berat Jenis dan Penyerapan Air Agregat Halus. Departemen Pekerjaan Umum Yayasan Badan Penerbit PU.

SNI 03-1971-1990. Metode Pengujian Kadar Air Agregat. Departemen Pekerjaan Umum Yayasan Badan Penerbit PU.

SNI 03-2816-1992. Metode Pengujian Kotoran Organik dalam Pasir untuk Campuran Mortar dan Beton. Departemen Pekerjaan Umum Yayasan Badan Penerbit PU.

SNI 03-4142-1996. Metode Pengujian Jumlah Bahan dalam Agregar yang Lolos Saringan No. 200 (0,075 mm). Departemen Pekerjaan Umum Yayasan Penerbit PU.

SNI 03-4804-1998. Metode Pengujian Bobot Isi dan Rongga Udara dalam Agregat. Departemen Pekerjaan Umum Yayasan Badan Penerbit PU.

SNI 03-6825-2002. Metode Pengujian Kekuatan Tekan Mortar Semen. Badan Standarisasi Nasional. Jakarta.

SNI 03-6882-2002. Spesifikasi Mortar untuk Pekerjaan Pasangan. Departemen Pekerjaan Umum Yayasan Badan Penerbit PU.

SNI 15-2049-2004. Semen Portland. Badan Standarisasi Nasional. Jakarta.

Wikana, I., dan Wantutrianus, Z. 2014. Pengaruh Pemakaian Fly Ash dan Abu Batu sebagai Pengganti Sebagian Semen pada Kuat Tekan Beton Mutu Tinggi, Majalah Ilmiah UKRIM Edisi 1/th $\mathrm{XIX} / 2014$. 